\title{
Sistem Monitoring Denyut Jantung Dan Suhu Tubuh Sebagai Indikator Level Kesehatan Pasien Berbasis IoT (Internet Of Thing) Dengan Metode Fuzzy Logic Menggunakan Android
}

\author{
${ }^{\mathrm{a} I n d r a}$ Prayogo, ${ }^{\mathrm{b}}$ Riza Alfita, ${ }^{\mathrm{c}}$ Kunto Aji Wibisono \\ ${ }^{a, b, c}$ Program Studi Teknik Elektro, Fakultas Teknik, Universitas Trunojoyo \\ a,b,c Jalan Raya Telang Bangkalan, Jawa Timur, Indonesia 69162 \\ E-mail: indraapraayogo@gmail.com,yogya_001@yahoo.co.id, kunto.utm@gmail.com
}

\begin{abstract}
Abstrak
Denyut jantung dan suhu tubuh merupakan salah satu faktor penentu atau tanda tanda vital dalam penentuan kesehatan. Denyut jantung dan suhu tubuh dilakukan untuk mengetahui tanda klinis dan berguna untuk memperkuat diagnosis suatu penyakit. Pada proses pemeriksaan denyut jantung dan suhu tubuh masih menggunakan sistem manual dimana pasien harus datang ke rumah sakit untuk memeriksa denyut jantung dan suhu tubuh. Sistem ini kurang efektif karena memakan banyak waktu. Pada penelitian ini dibuat sebuah sistem monitoring denyut jantung dan suhu tubuh sebagai indikator level kesehatan pasien berbasis iot (internet of things) dengan metode fuzzy menggunakan android. Sistem ini menggunakan pulse sensor untuk mendeteksi denyut jantung dan LM35DZ untuk mendeteksi suhu tubuh. Pemroses data menggunakan arduino uno dan nodemcu yang sekaligus berfungsi sebagai media pengiriman data menggunakan internet of things. Sistem ini mendeteksi denyut jantung dan suhu tubuh jarak jauh. Sistem ini dilengkapi dengan fitur interface android dan desktop, simpan data dan keputusan sehat atau tidak. Dari hasil pengujian tingkat keberhasilan mendeteksi denyut jantung adalah $97.71 \%$, suhu tubuh sebesar 99.69\%, tingkat keberhasilan pengiriman data sebesar 50\%, dan keputusan sesuai dengan rule kesehatan yang telah ditentukan. Dari hasil tersebut sistem sesuai dengan yang diharapkan.
\end{abstract}

Kata kunci: Denyut Jantung, Internet of things, Monitoring, Sistem, Suhu Tubuh.

\section{PENDAHULUAN}

Kesehatan merupakan hal penting dalam kehidupan manusia. Kesehatan adalah keadaan baik dari badan, jiwa dan social yang memungkinkan setiap orang hidup sehat. Penentuan kesehatan dapat dilakukan dengan pemeriksaan TTV (Tanda Tanda Vital). Pemeriksaan tanda vital merupakan pengukuran fungsi tubuh yang paling dasar untuk mengetahui tanda klinis dan berguna untuk memperkuat diagnosis suatu penyakit dan berfungsi dalam menentukan perencanaan medis yang sesuai[1].

Denyut Jantung dalah jumlah panas ketukan dalam satu menit atau jantung denyut per menit sementara denyut nadi adalah ukuran tekanan darah meningkat teraba seluruh tubuh. Denyut nadi adalah berapa kali arteri kita berdenyut permenit yang sebagai dampak dari berdenyutnya jantung. Frekuensi denyut nadi akan sama persis dengan detak jantung, tekanannya juga akan menggambarkan tingkat kontraksi jantung, karena kontraksi jantung ini menyebabkan peningkatan tekanan darah dan denyut nadi di arteri[2]. Dalam pengukuran denyut nadi dan denyut nadi merupakan hal yang sama. Denyut jantung digunakan untuk parameter fungsi tubuh manusia, yang berkisar antara 60-100 denyut permenit untuk usia dewasa[3]. Rata-rata kecepatan detak jantung menunjukkan aktifitas jantung. Denyut jantung tidak sehat terbagi menjadi dua klasifikasi yaitu bradikardia dan takikardia. Bradikardia adalah istilah untuk denyut jantung kurang dari 60. Pada sebagian orang denyut jantung kurang dari $60 \mathrm{bpm}$ tidak menimbulkan gejala apapun, namun sebagian orang lainnya denyut jantung kurang dari 60 
merupakan tanda masalah sistem kelistrikan pada jantung. Bradikardia menyebabkan darah tidak dapat terdistribusi dengan baik ke seluruh tubuh, bahkan dapat menyebabkan kematian. Denyut jantung melebihi $100 \mathrm{bpm}$ merupakan istilah dari takikardia. Takikardia dapat menyebabkan denyut jantung memiliki ritme yang abnormal serta serangan jantung.

Tanda vital juga dapat melalui suhu tubuh manusia. Suhu tubuh adalah perbedaan antar jumlah panas yang diproduksi oleh proses tubuh dan jumlah panas yang hilang kelingkungan luar. Suhu tubuh mudah sekali berubah dan dipengaruhi oleh banyak faktor, baik faktor eksternal maupun faktor internal. Perubahan suhu tubuh sangat erat kaitannya dengan produksi panas maksimal maupun pengeluaran panas yang berlebihan. Sifat perubahan panas tersebut sangat mempengaruhi masalah klinis yang dialami setiap orang, menurutu WHO suhu tubuh normal manusia berkisar 36,5$37,5{ }^{\circ} \mathrm{C}[4]$.

Denyut jantung dan suhu tubuh sangat berpengaruh terhadap kesehatan dan bagi penderita penyakit jantung akan sangat fatal jika pertolongan pertama tidak cepat dilakukan. Kesehatan berdasarkan denyut jantung dan suhu tubuh dapat berubah sesuai dengan pola hidup, sehingga perubahan kesehatan dapat berubah secara tiba-tiba. Perubahan kesehatan atau sakit biasanya diketahui setelah pasien diperiksa ke dokter. Hal tersebut membutuhkan waktu dan jarak untuk mencapai rumah sakit, sehingga kurang efisien.

Dengan membangun sebuah sistem monitoring denyut jantung dan suhu tubuh pasien berbasis IOT ini diharapkan kondisi pasien dapat dipantau secara langsung (online), dengan melalui android dan desktop sehingga data-data denyut jantung dan suhu tubuh kesehatan pasien dapat setiap saat dipantau oleh dokter dan keluarga.Sistem berbasi IOT agar jarak tidak menjadi kendala dalam proses monitoring. IOT merupakan sebuah konsep yang bertujuan untuk memperluas dan memanfaatkan konektivitas yang tersambung secara terus-menerus. IOT dapat digunakan dengan menggunakan access point yang berbeda sehingga koneksi tidak menjadi kendala. IOT dapat diterapkan dalam berbagai bidang seperti dalam bidang kesehatan. IOT dapat digunakan untuk memonitor kondisi pasien, sehingga kondisi pasien tetap terpantau 24 jam.
Dengan menggunakan server bernama ubidots. Ubidots adalah sebuah platform IOT. Ubidots memiliki layanan notifikasi sms dan email jika dengan trigger yang dibuat berdasarkan data sensor yang user tetapkan sebelumnya. Ubidots memiliki fasilitas yaitu data diambil oleh software yang dibuat.

Agar sistem dapat bekerja dengan baik, maka digunakan dua interface yaitu menggunakan android dan desktop. Dua interface dapat di monitoring bersamaan atau terpisah. Pada kedua interface menggunakan database agar data hasil monitoring dapat disimpan dan dilihat berdasarkan tanggal dan jam.

Untuk lebih meningkatkan efektifitas serta fungsi dari sistem, maka perlu diaplikasikan algoritma fuzzy mamdani sebagai penentu status dari pasien berdasarkan bpm dan suhu, diharapkan sistem yang digunakan dalam penelitian ini dapat bekerja dengan baik sehingga bias didapatkan data deteksi kondisi denyut jantung dan suhu tubuh pasien.

\section{BAHAN DAN METODE}

Metode penelitian yang digunakan pada tugas akhir ini melalui beberapa tahapan penelitian dan mencari informasi tentang data yang dibutuhkan dalam melakukan tugas akhir. Penelitian pertama adalah pengembangan konsep penelitian berdasarkan daftar pustaka. Selanjutnya perencanaan penelitian meliputi perancangan sistem perangkat keras dan perangkat lunak. Informasi data meliputi pulse sensor dan LM35 sebagai input data denyut nadi dan suhu pada alat secara real time, kemudian diproses dalam mikrokontroler Arduino uno dan ESP8266 (Node MCU), serta interface yang digunakan untuk memonitoring.

Setelah didapatkan informasi mengenai halhal yang dibutuhkan maka langkah selanjutnya adalah membuat skrip perancangan sistem menggunakan pemograman $\mathrm{C}$ pada arduino IDE, pemograman java pada android studio dan pemograman delphi pada delphi xe 8. Setelah mengetahui informasi mengenai hal-hal yang dibutuhkan maka selanjutnya melakukan perancangan sistem yang ditnjukkan pada gambar 1 


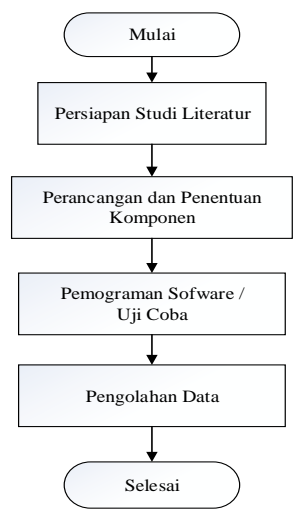

Gambar 1. Bagan Tahap Proses Perancangan

Sistem

Gambar 6. merupakan tahap proses perancangan sistem yang akan di lakukan. Pada bagian ini proses dapat di bagi menjadi dalam tiga kelompok. Tahap pertama yang dilakukan adalah meyiapkan hardware yang dibutuhkan dalam sistem dan studi literatur pulse sensor, ubidots dan http get request. Tahap kedua yaitu membuat skrip pada software arduino IDE yang selanjutnya diupload ke dalam mikrokontroler arduino uno dan node mcu. Tahap ketiga adalah melakukan pengambilan data yang di terima oleh server ubidots, kemudian data yang telah di ambil di proses yang selanjutnya akan di tampilkan pada android dan desktop yaitu delphi.

A. Block Diagram Sistem

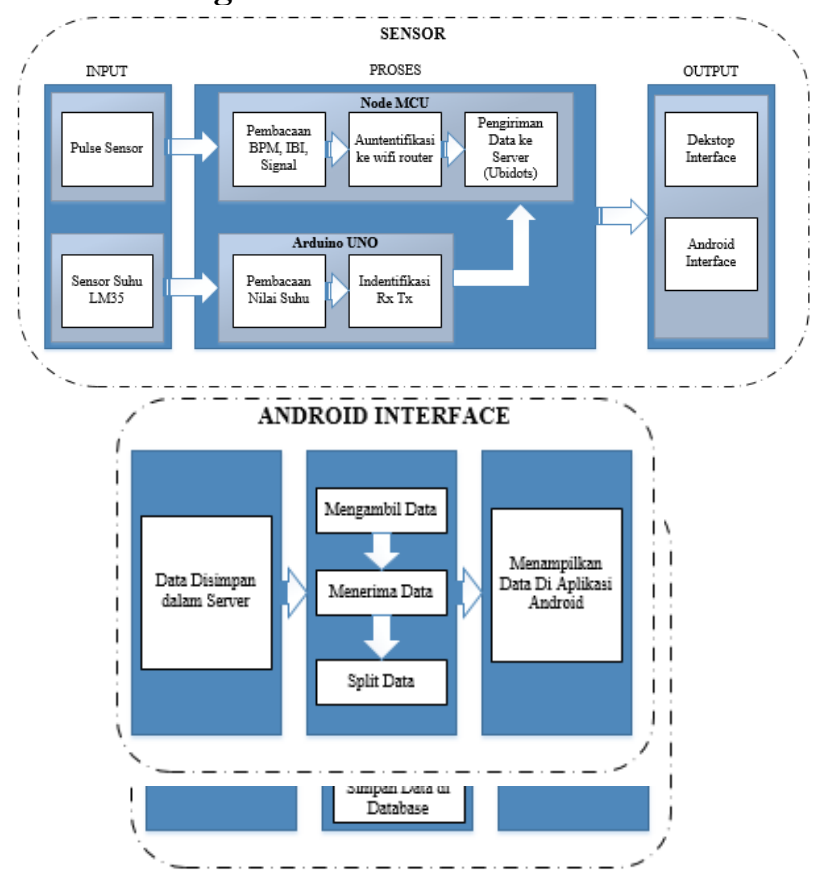

Gambar 2. Block Diagram Sistem
Pada gambar 2 sensor terdiri dari dari dua sensor yaitu pulse sensor dan sensor suhu LM35. Pulse sensor berfungsi untuk mendeteksi bpm (beat per minutes) yaitu denyut jantung atau denyut nadi yang di deteksi berdasarkan aliran darah yang di pompa oleh jantung, IBI yaitu waktu interval antara nilai bpm yaitu data tegangan yang diterima lalu ditampilkan

Pada sensor suhu LM35 juga di hubungkan pada port Analog Input agar dapat di deteksi nilai dari sensor tersebut. Kemudian nilai dari sensor tersebut di konversi menjadi suhu dengan satuan derajat dengan rumus yang sudah di aplikasikan pada mikrokontroler. Arduino uno merupakan slave pada sistem yang digunakan untuk pemrosesan data pada sensor suhu LM35 dimana data sensor di konversi menggunakan rumus yang telah di buat pada program sehingga dapat menghasilkan data suhu denga satuan derajat. Kemudian data suhu yang diperoleh dikirimkan ke mikrokontroler node mcu melalu komunikasi serial dengan bantuan $\mathrm{Rx}$ Tx (Receiver and Transmitter). Pengiriman data melalui serial tersebut sudah di lakukan inisialisasi pin Rx Tx pada arduino uno agar dapat terkirim.

Pada node mcu sebagai master merupakan inti dari mikrokontroler yang berfungsi sebagai pemroses data dan pengirim data pada server. Pada node mcu pulse sensor diolah untuk mendapatkan data bpm, ibi dan signal. Pada penerimaan data node mcu juga menginisialisasi pin $\mathrm{Rx}$ Tx agar data dapat di terima dengan baik. Setelah data pulse sensor di olah dan data suhu diterima maka data tersebut dikirim pada server menggunakan acces point wireless yang telah di pilih.

Setelah data berhasil dikirim ke server makan selanjtunya data tersebut di simpan dalam server tersebut. Kemudian data tersebut di ambil menggunakan http get request yang selanjutnya dapat di olah pada android dan delphi monitor yang telah di buat. Dari data yang diterima kemudian di pisah (split) sehingga dapat mengambil data angka dalam bentuk string yang selanjutnya di tampilkan pada android interface dan delphi interface.

\section{B. Algoritma Sistem}

Dari gambar 3 di jelaskan bahwa prinsip dari sistem ini adalah memonitoring denyut jantung dan suhu tubuh secara real time. Kondisi awal sistem adalah membaca data sensor dan kemudian mengirimkan data dari arduino uno ke node mcu melalui komunikasi serial $\mathrm{Rx} T \mathrm{Tx}$. Selanjutnya mengauntentifikasi ke wifi router dan kemudian 
mengirim data ke server (ubidots). Data yang terkirim ke server akan di simpan dalam server tersebut. Kemudian data yang telah terkirim dan tersimpan dalam server akan di ambil oleh perangkat lunak yang telah dibuat. Perangkat lunak mengolah data dan di tampilkan pada android dan desktop (delphi). Setiap perubahan data yang terjadi maka node mcu akan merespon perubahan tersebut sesuali algoritma di gambar 3.5. Apabila tidak terjadi perubahan, maka proses otomatis akan berulang kembali menuju proses pembacaan dan pengiriman data yang akan dilakukan pada sistem.

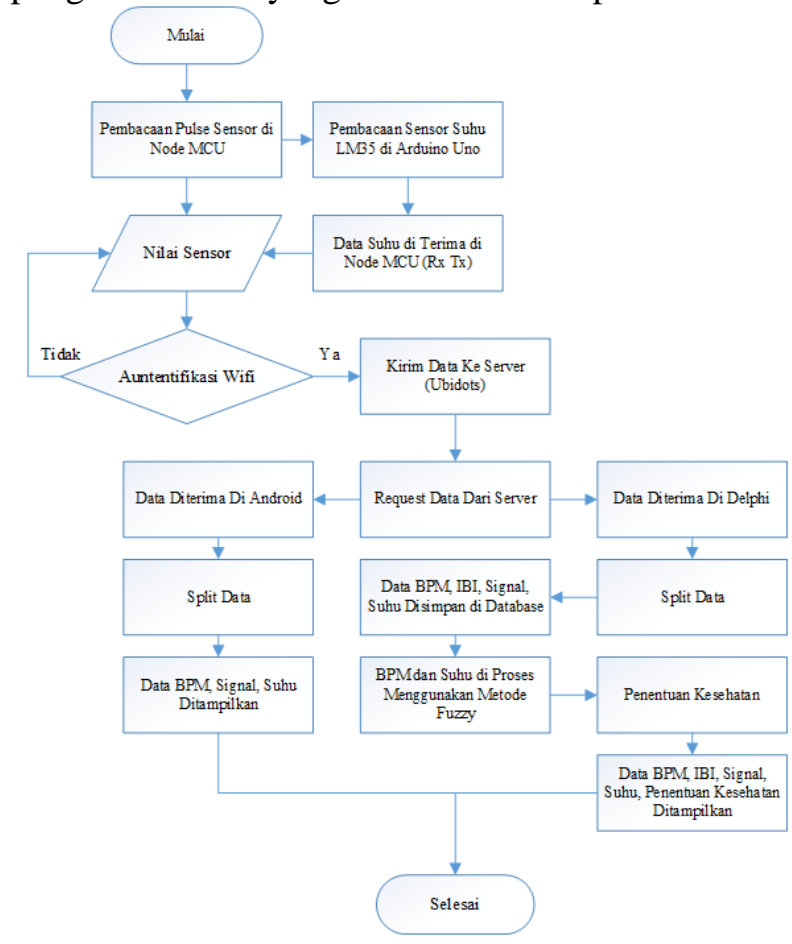

Gambar 3. Flowchart Sistem

\section{Algoritma Koneksi Ke Server Ubidots}

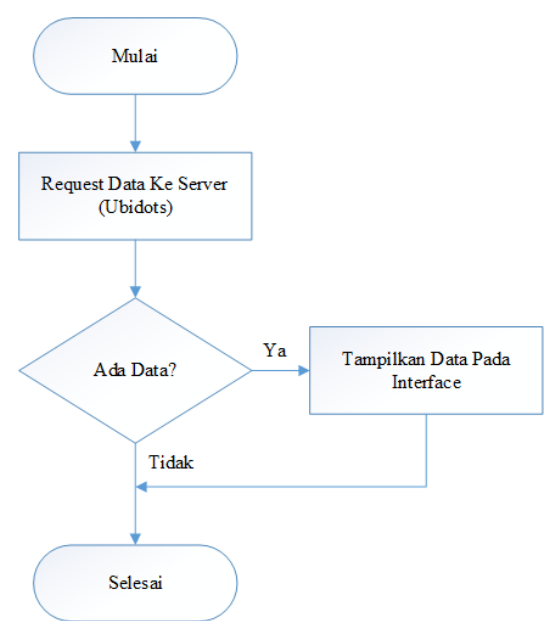

Gambar 4. Flowchart Pengiriman Data Ke Server
Dari gambar 4 dapat di ketahui bahwa dalam pengiriman data ke server adalah dengan cara memproses data pada mikrokontroler. Kemduian mikrokontroler mencari acces point sebagai perantara dalam pengiriman data. Jika koneksi gagal atau tidak menemukan acces point akan melakukan callback wifi atau mencarai acces point lain. Jika koneksi berhasil data dikirim pada pada server ubidots dan data di simpan dalam server tersebut.

\section{Algoritma Monitor}

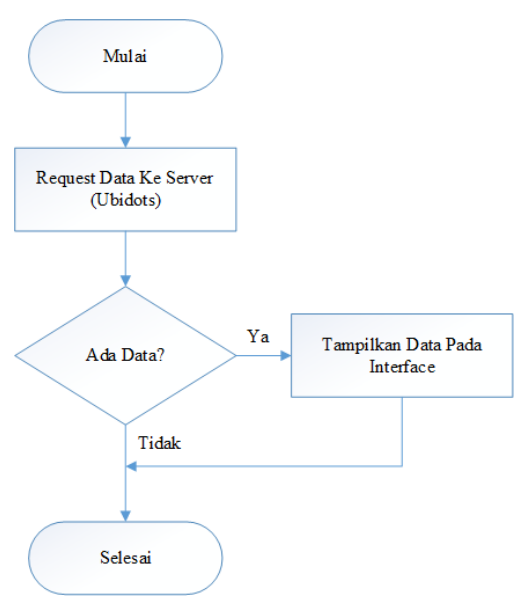

Gambar 5. Flowchart Interface

Interface menggunakan android interface dan desktop interface dengan koneksi jaringan enggunakan kabel LAN (Local Area Network) atau Wireless. Program di implementasikan menggunakan Bahasa java pada android studio dan delphi pada delphi xe 8. Dari flowchart 10 data di ambil dengan cara request data ke server ubidots. Jika ada data maka data akan di proses pada perangkat lunak lalu di tampilkan. Jika tidak ada maka perangkat lunak akan me-request lagi data pada server.

\section{HASIL DAN PEMBAHASAN}

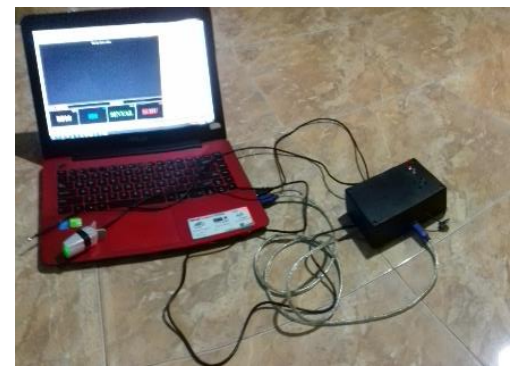

Gambar 6. Implementasi Sistem 


\section{A. Pengujian Pulse Sensor}

Dalam proses pengujian data dilakukan dengan cara pengujian respon pulse sensor setiap jari pada tangan terlebih dahulu agar diketahui jari yang mempunyai tingkat pengukuran yang lebih akurat.

\begin{tabular}{|c|c|c|}
\hline $\begin{array}{ll} & 1 \\
\end{array}$ & Jari & $\begin{array}{l}\text { Denyut Jantung } \\
\text { (BPM) }\end{array}$ \\
\hline. & Jempol & 80 \\
\hline 2 & Telunjuk & 79 \\
\hline 2 & Jari Tengah & 79 \\
\hline 4 & Jari Manis & 80 \\
\hline 5 & Kelingking & 79 \\
\hline$t$ & > Ruas Jari & 116 \\
\hline
\end{tabular}

Dari table 4.1 didapatkan hasil yang tidak jauh berbeda dalam pengukuan setiap jari. Penggunaan pulse sensor lebih dari ruas jari dihasilkan nilai bpm yang jauh berbeda. Dari hasil tersebut dapat diketahui bahwa setiap jari pada tangan dapat dijadikan sebagai tolak ukur dalam pengukuran bpm.

Pada pengujian dilakukan dengan mengambil data dari 7 objek dengan pengambilan sampel sebanyak 5 kali. Pengambilan data 5 kali dari masing-masing objek penelitian bertujuan untuk mengambil nilai rata-rata dari perhitungan yang dihasilkan oleh sensor. Hasil perhitungan dari sensor kemudian dibandingkan dengan hasil perhitungan secara manual yang diambil dengan cara menghitung denyut nadi masing-masing objek selama 10 detik. Perhitungan secara manual diambil sebagai tolak ukur untuk hasil penghitungan dari pulse sensor agar dapat menentukan seberapa besar error yang dialami pada saat pembacaan dengan pulse sensor.
Tabel 2. Hasil Pengujian Pulse Sensor

\begin{tabular}{|c|c|c|c|c|}
\hline \multirow{2}{*}{ No } & \multirow{2}{*}{ Nama } & \multicolumn{2}{|c|}{$\begin{array}{c}\text { Denyut Jantung } \\
(\mathrm{BPM})\end{array}$} & \multirow{2}{*}{ Error(\%) } \\
\hline & & $\begin{array}{l}\text { Pulse } \\
\text { Sensor }\end{array}$ & Manual & \\
\hline 1. & Objek 1 & 91 & 94 & 3.19 \\
\hline 2. & Objek 2 & 81 & 80 & 1.25 \\
\hline 3. & Objek 3 & 69 & 70 & 1.42 \\
\hline 4. & Objek 4 & 84 & 84 & 0 \\
\hline 5. & Objek 5 & 65 & 67 & 2.98 \\
\hline 6. & Objek 6 & 81 & 78 & 3.84 \\
\hline 7. & Objek 7 & 92 & 89 & 3.37 \\
\hline \multicolumn{4}{|c|}{ a Error(\%) } & 2.29 \\
\hline
\end{tabular}

Dari tabel 2 di dapatkan nilai error terbesar $3.84 \%$ dan error terkecil $0 \%$, dimana rata-rata error dari pengujian pulse sensor sebanyak 7 objek adalah $2.29 \%$.

\section{B. Pengujian LM35DZ}

Pada pengujian sensor suhu LM35DZ, pengujian dilakukan dengan cara memasangkan sensor pada ketiak objek karena ketiak merupakan bagian tubuh yang bisa dijadikan patokan dengan cara menunggu $2-3$ menit pembacan sensor. Sama dengan pengujian sensor LM35DZ, pengujian dilakukan dengan mengambil data dari 7 objek dengan pengambilan sampel sebanyak 5 kali. Pengambilan data 5 kali dari masing-masing objek penelitian bertujuan untuk mengambil nilai rata-rata dari perhitungan yang dihasilkan oleh sensor. Hasil perhitungan dari sensor kemudian dibandingkan dengan hasil termometer digital dengan cara menunggu 2 - 3 menit agar dihasilkan pembacaan suhu. Termometer digital dijadikan sebagai tolak ukur untuk hasil penghitungan dari sensor LM35DZ agar dapat menentukan seberapa besar error yang dialami pada saat pembacaan dengan sensor LM35DZ.

Tabel 3. Hasil Pengujian Sensor LM35DZ

\begin{tabular}{ccccc}
\hline \multirow{2}{*}{ No } & \multirow{2}{*}{ Nama } & \multicolumn{2}{c}{ Suhu Tubu $\left({ }^{0} \mathrm{C}\right)$} & \multirow{2}{*}{ Error $(\%)$} \\
\cline { 3 - 4 } & & LM35DZ & Manual & \\
\hline 1. & Objek 1 & 36.2 & 36.1 & 0.27 \\
2. & Objek 2 & 36.8 & 36.7 & 0.27 \\
3. & Objek 3 & 36.3 & 36.3 & 0 \\
4. & Objek 4 & 36.4 & 36.4 & 0 \\
5. & Objek 5 & 37 & 36.8 & 0.54 \\
6. & Objek 6 & 36.2 & 36 & 0.56 \\
7. & Objek 7 & 36.6 & 36.8 & 0.54 \\
\hline \multicolumn{5}{c}{ Rata-rata Error(\%) } \\
\hline
\end{tabular}


Dari tabel 3 didapatkan error yaitu $0.54 \%$ dan error terkecil adalah $0 \%$. Pengujian sensor LM35DZ didapatkan error rata-rata sebesar $0.31 \%$.

\section{Pengujian Sistem}

Pengujian sistem dilakukan dengan cara mengirimkan 30 data sensor ke server ubidots. Pengujian keseluruhan sistem bertujuan untuk mengetahui apakah sistem yang dirancang dapat berfungsi dengan baik sesuai dengan yang diharapkan. Hasil pengujian keseluruhan dilakukan pengiriman data ke server ubidots dan pengambilan data dari ubidots ke interfaces pada sistem monitoring.

Tabel 4. Pengujian Keberhasilan Data

\begin{tabular}{|c|c|c|c|c|c|}
\hline Jam & BPM & IBI & Signal & Suhu & Status \\
\hline $\begin{array}{c}10: 20: 53 \\
\text { AM }\end{array}$ & 85 & 766 & 972 & 36.87 & Normal \\
\hline $\begin{array}{c}10: 20: 57 \\
\text { AM }\end{array}$ & 79 & 764 & 218 & 36.97 & Normal \\
\hline $\begin{array}{c}\text { 10:21:01 } \\
\text { AM }\end{array}$ & 79 & 756 & 971 & 36.87 & Normal \\
\hline $\begin{array}{c}10: 21: 01 \\
\text { AM }\end{array}$ & 77 & 828 & 197 & 36.97 & Normal \\
\hline $\begin{array}{c}10: 21: 05 \\
\text { AM }\end{array}$ & 77 & 698 & 798 & 36.97 & Normal \\
\hline $\begin{array}{c}10: 21: 10 \\
\text { AM }\end{array}$ & 81 & 710 & 285 & 36.87 & Normal \\
\hline $\begin{array}{c}10: 21: 15 \\
\text { AM }\end{array}$ & 80 & 726 & 972 & 36.97 & Normal \\
\hline $\begin{array}{c}10: 21: 15 \\
\text { AM }\end{array}$ & 82 & 704 & 288 & 36.97 & Normal \\
\hline $\begin{array}{c}10: 21: 19 \\
\text { AM }\end{array}$ & 83 & 734 & 215 & 36.97 & Normal \\
\hline $\begin{array}{c}10: 21: 23 \\
\text { AM }\end{array}$ & 84 & 684 & 685 & 36.87 & Normal \\
\hline $\begin{array}{c}10: 21: 23 \\
\text { AM }\end{array}$ & 84 & 696 & 971 & 36.87 & Normal \\
\hline $\begin{array}{c}10: 21: 27 \\
\text { AM }\end{array}$ & 86 & 688 & 162 & 36.87 & Normal \\
\hline $\begin{array}{c}10: 21: 31 \\
\text { AM }\end{array}$ & 87 & 672 & 971 & 36.97 & Normal \\
\hline $\begin{array}{c}10: 21: 33 \\
\text { AM }\end{array}$ & 87 & 672 & 298 & 36.87 & Normal \\
\hline $\begin{array}{c}10: 21: 37 \\
\text { AM }\end{array}$ & 86 & 702 & 298 & 36.87 & Normal \\
\hline
\end{tabular}

Dari tabel 4.6 di dapatkan data sebanyak 15. Sensor mengirimkan data sebanyak 30 pada server dan berhasil diambil oleh interface sebanyak 15 . Setiap pengiriman 2 data dari sensor, interface dapat menangkap 1 data. Dimana 1 data sisanya tidak dapat diterima dengan baik atau lost. Dari data yang diterima di dapatkan persentase data sukses sebagai berikut:

$$
\text { Data Sukses }=\frac{15}{30} x 100 \%=50 \%
$$

Pengujian sistem juga dapat di hasilkan keputusan sesuai dengan metode fuzzy mamdani yang digunakan dimana input yang dimasukkan berdasarkan bpm dan suhu berdasarkan range yang telah ditentuka pada himpunan fuzzy. Kemudian dari input di dapatkan output kesehatan.

Uji sistem yang dilakukan bertujuan untuk mengetahui keseluruhan sistem termasuk interface yang dirancang untuk menampilkan data dari sensor

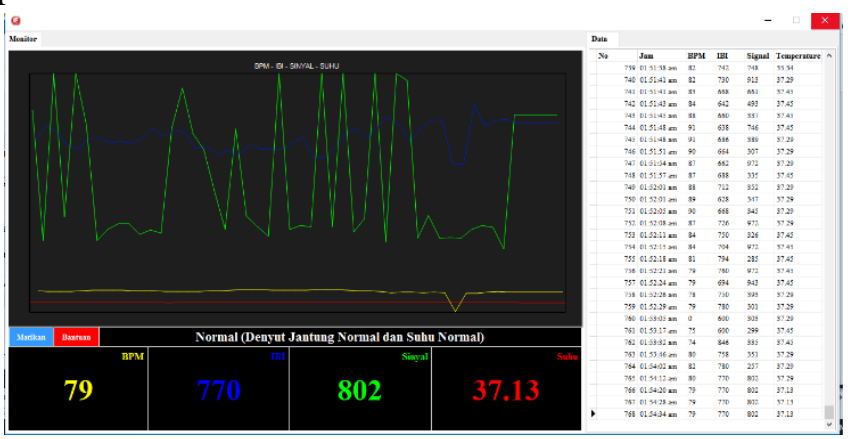

Gambar 7. Tampilan Monitoring Menggunakan Desktop Interface

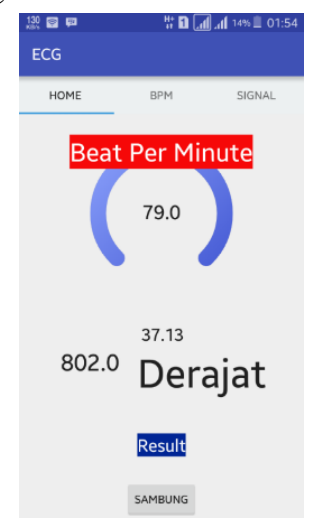

Gambar 8. Tampilan Monitoring Menggunakan Android Interface

\section{Pembahasan}

Dari pengujian yang telah dilakukan dapat di simpulkan bahwa sistem dapat berjalan dengan baik dan sesuai dengan perancangan. Hal tersebut berdasarkan data-data yang diperoleh pada saat uji 
coba dan mencocokkan data dengan pengukuran yang sudah ada sebelumnya.

Pada uji coba pulse sensor dilakukan dengan mengambil data pada 7 objek yang berbeda. Pada uji coba pengukuran bpm setiap jari didapatkan hasil yang tidak jauh berbeda dari setiap jari, dimana setiap jari dapat digunakan untuk mengujur bpm. Dari pengambilan data yang telah dilakukan didapatkan error rata-rata sebesar $2.29 \%$, dimana error terbesar yang didapatkan adalah $3.84 \%$ dan error terkecil 0\%. Error tersebut disebabkan karena kondisi objek pada saat pengukuran menggunakan sensor serta human error pada perhitungan bpm manual. Kondisi objek sangat berpengaruh pada pembacaan pulse sensor, apabila objek dalam keadaan sakit, banyak pikiran, takut dan lain-lain maka pulse sensor akan membaca data sesuai yang diukur pada objek. Human error pada perhitungan manual bpm sangat berpengaruh dalam uji coba, karena akan mempengaruhi ᄀerror uji coba dimana pengukuran pulse sensor dibandingkan dengan perhitungan manual. Human error dapat berupa kesalahan menghitung serta posisi tangan dalam pembacaan denyut.

Kemudian pada pengambilan data sensor LM35DZ dilakukan dengan mengambil data dari 7 objek yang selanjutnya dibandingkan dengan alat ukur termometer. Dari uji coba yang dilakukan di dapatkan error terbesar yaitu $0.54 \%$ dan error terkecil $0 \%$, dimana dari 7 objek didapatkan error rata-rata $0.31 \%$. Error tersebut disebabkan oleh posisi penggunaan sensor LM35DZ, suhu lingkungan, serta penggunaan termometer digital. Posisi penggunaan sensor cukup berpengaruh, apabila penempatan sensor dibawah atau melebihi ketiak maka pembacaan sensor akan sedikit berbeda. Kemudian sensor LM35DZ yang tidak dirapatkan oleh lengan pada saat pengukuran, maka suhu lingkungan akan berpengaruh pada pembacaan sensor. Hal tersebut dikarenakan sensor LM35DZ sensitif terhdapat suhu lingkungan, sehingga dalam penggunaannya dirapatkan oleh lengan untuk meminimalisir hal tersebut. Disamping itu penggunaan termometer yang kurang tepat akan berpengaruh terhadap perbandingan nilai suhu tubuh.

Selanjutnya pengujian sistem yang bertujuan untuk mengetahui tingkat kerja sistem. Pengujian dilakukan dengan mengirim data pulse sensor dan sensor LM35DZ sebanyak 30 ke server ubidots. Kemudian pengambilan data oleh aplikasi serta proses monitoring, dimana data yang berhasil diterima oleh interface sebanyak 15. Dari uji coba tersebut dapat diketahui bahwa setiap pengiriman 2 data sensor pada server, aplikasi dapat mengambil 1 data dimana 1 data yang lain lost. Hal tersebut dikarenakan koneksi yang digunakan yaitu koneksi pengirim dan koneksi penerima. Koneksi pengirim dan koneksi penerima sangat berhubungan dalam penerimaan data, apabila salah satu tidak baik maka peluan data untuk lost akan lebih besar. Dari data yang diterima didapatkan data sukses sebesar 50\%. Pada uji coba metode didapatkan hasil yang sesuai dengan himpunan yang ditampilkan pada keputusan. Keputusan akan berubah sesuai dengan data bpm dan suhu tubuh yang diukur.

\section{KESIMPULAN}

Berdasarkan hasil dapat ditarik kesimpulan sebagai berikut:

1. Akurasi perhitungan menggunakan pulse sensor dan sensor LM35DZ terbilang akurat. Rata-rata error yang yang dihasilkan dari perhitungan denyut jantung menggunakan pulse sensor sebanyak $2.29 \%$. Sedangkan rata-rata error yang dihasilkan pada perhitungan suhu tubuh menggunakan LM35DZ sebanyak $0.31 \%$.

2. Pengiriman dan penerimaan data berbasis internet of things dapat bekerja dengan baik dengan tingkat kesuksesan data sebesar $50 \%$ berdasarkan koneksi internet.

3. Penggunaan metode fuzzy mamdani pada aplikasi dapat berjalan dengan baik sesuai dengan rule yang sudah ditentukan.

4. Fungsional sistem dalam menampilkan hasil monitoring telah sesuai dengan yang diharapkan.

\section{DAFTAR PUSKATA}

[1] M. A. Saputro, E. R. Widasari and H. Fitriyah, "Implementasi Sistem Monitoring Detak Jantung dan Suhu Tubuh Manusia Secara Wireless," Jurnal Pengembangan Teknologi Informasi dan Ilmu Komputer, Vols. 1, No. 2, pp. 148-156, 2 Februari 2017.

[2] d. A. Muhlisin, "Detak Jantung Normal," 2017. [Online]. Available: https://mediskus.com/dasar/detak-jantungnormal. [Accessed 2 Agustus 2017]. 
[3] I. N. Sandi, "Hubungan Antara Tinggi Badan, Berat Badan, Indeks Massa Tubuh, Dan Umur Terhadap Frekuensi Denyut Nadi Istirahat Siswa Smkn-5 Denpasar," Sport and Fitness Journal, Vols. 1, No. 1, pp. 38 - 44, Juni 2013.

[4] N. M. E. M, "Penyebab Bradikardia, Denyut Jantung Lemah Berakibat Fatal," helloSehat, 20 Januari 2017. [Online]. Available: https://hellosehat.com/bradikardia-denyutjantung-lemah/. [Accessed 29 Juli 2017]. 